


\title{
Evaluation of the protective efficacy of Salmonella Gallinarum 9R strain vaccine against Salmonella strains isolated from cases suspected of salmonello- sis outbreaks in poultry farms in central Ethiopia
}

Kassaye Adamu, Hundera Sori, Esayas Gelaye, Alebachew Belay, Gelagay Ayelet, Martha Yami and Takele Abayneh*

National Veterinary Institute, P.O. Box 19, Debre-Zeit, Ethiopia

*Corresponding author: Takele Abayneh, National Veterinary Institute, P.O.Box 19, Debre-zeit, Ethiopia E-mail:takeletefera99@gmail.com Tel: +251911407632

https://dx.doi.org/10.4314/evj.v21i1.9

\begin{abstract}
Salmonellosis is one of the most important bacterial diseases of poultry causing heavy economic losses. Though it can be prevented through vaccination, regular monitoring of the protective efficacy of the vaccine against field outbreaks is essential since antigenically dissimilar serovars may evolve compromising the efficacy of the vaccine. This study was, therefore, carried out to evaluate the protective efficacy of the currently used attenuated Salmonella Gallinarum 9R strain vaccine against experimental challenge with field isolates of Salmonella strains obtained from disease outbreaks. Three Salmonella serovars viz Salmonella Gallinarum, Salmonella Pullorum and Salmonella Enteritidis isolated and identified (phenotypically and molecularly) from outbreaks suspected of salmonellosis were used for the challenge experiment. A total of 90 chickens randomly divided into 2 categories (vaccinated and non-vaccinated control) each comprising 45 birds were used for protective efficacy study. Each of these categories were further subdivided and randomly assigned into 3 groups each comprising 15 birds for challenge with each of the three field Salmonella serovars. Chickens were vaccinated subcutaneously with live attenuated Salmonella Gallinarum 9R vaccine containing 2x107 CFU per dose. Each group in both vaccinated and non vaccinated category were challenged with the three field serovars (one strain per group) through oral administration of $1 \mathrm{ml}$ of bacterial suspension containing $5 \times 10^{7}$ organisms. Post challenge follow-up showed no mortality in all vaccinated groups challenged with each of the three serovars while a mortality of $53.3 \%(\mathrm{~N}=8), 13.3 \%(\mathrm{~N}=2)$ and $0 \%$ was observed in $S$. Gallinarum, S. Pullorum and $S$. Enteritidis challenged nonvaccinated groups, respectively. None of the challenge Salmonella strains were
\end{abstract}

Ethiop. Vet. J., 2017, 21 (1), 102-116 
recovered from liver and spleen of the vaccinated birds two weeks after challenge. In conclusion, the currently used attenuated $S$. Gallinarum 9R strain vaccine against fowl typhoid can effectively confer protection not only against field strains of Salmonella Gallinarum, but also cross-protection to S. Pullorum and $S$. Enteritidis involved in causing poultry salmonellosis outbreaks in Ethiopia.

Keywords: Central Ethiopia; Poultry; Salmonellosis; Vaccine efficacy

\section{Introduction}

Salmonellosis is one of the most important bacterial diseases in poultry industry causing heavy economic loss through mortality and reduced productivity. The disease is most significant because the causal agents of the disease are transmitted vertically from parents to offsprings (Freeman, 1985). There are mainly two serotypes of Salmonella enterica. namely Salmonella enterica subspecies enterica serovar Gallinarum biovar Gallinarum and Salmonella enterica subspecies enterica serovar Gallinarum biovar Pullorum that cause fowl typhoid and pullorum disease, respectively. Although mostly restricted to the gastrointestinal tract (GIT), invasive forms of S. Enteritidis are occasionally reported in causing salmonellosis in poultry (Barbour et al., 1999; Hinton et al., 1990). Salmonellae may cause varieties of clinical signs ranging from acute systemic disease and gastrointestinal symptoms in poultry flocks to embryonic problem in hatchery (Gast, 1997). Pullorum disease is usually confined to the first 2-3 weeks of age with occasional occurrence in adults Shivaprasad, (1997) while Fowl typhoid (FT) is frequently referred to as a disease of adult birds although there are also reports of high mortality in young birds indistinguishable from those associated with pullorum disease (Threlfall and Frost, 1990).

Fowl typhoid constitutes a considerable economic problem for poultry growers in developing countries. With great expansion of poultry rearing and farming, pullorum disease and fowl typhoid have become widespread problem in Ethiopia like other countries of the world causing heavy economic losses in broiler, layer and breeding flocks. Vaccination of chickens seems to be the most effective strategy to control the disease along with increased bio-security measures to avoid pathogen introduction into poultry farms. The available vaccine that has long been used in Ethiopia against the disease is a live vaccine based on attenuated Salmonella Gallinarum 9R strain. However, population shifts have been reported in Salmonella serovars due to the selective pressure result- 
ing from over years of vaccination targeting specific serovars in commercial poultry-associated environments (Foley et al., 2011). Since the efficacy of a vaccine against antigenically dissimilar serovars is reduced or absent (Foley et al., 2011), regular monitoring of the protective efficacy of the vaccine against field outbreaks is essential.

The present work is, therefore, undertaken with the objectives of evaluating of the protective efficacy of the currently used live attenuated Salmonella Gallinarum 9R strain vaccine against experimental challenge with Salmonella serovars currently isolated from cases of salmonellosis outbreaks.

\section{Materials and Methods}

\section{Salmonella strains}

Salmonella serovars used for the challenge experiment were isolated from a total of 14 disease outbreaks suspected of salmonellosis in different commercial layer poultry farms in central Ethiopia during the period November 2014 to June 2015. In all the farms with the recorded outbreaks, the chickens were not vaccinated against salmonellosis.

\section{Isolation and identification of Salmonella strains}

Specimen for bacteriology were collected aseptically from tissue with typical pathological lesions found in different internal organs (liver, heart, and spleen) after euthanizing by cervical dislocation of clinically suspected chicken. Samples were collected from all ages. Bacterial isolation and identification were done at the National Veterinary Institute, Ethiopia. Pooled samples of internal organs (from each case) were homogenized and pre-enriched in buffered peptone water for $24 \mathrm{~h}$ at $37^{\circ} \mathrm{C}$, followed by an enrichment step in RappaportVassiliadis broth for $48 \mathrm{~h}$ at $42^{\circ} \mathrm{C}$. Droplets of the Rappaport-Vassiliadis broth were spread onto Brilliant Green Agar and Salmonella Shigella agar and incubated for $48 \mathrm{~h}$ at $37^{\circ} \mathrm{C}$. Colonies showing typical morphological characteristics of Salmonella were sub-cultured to get pure cultures for further biochemical and molecular identification (OIE, 2014).

Biochemical tests used for $S$. Gallinarum and $S$. Pullorum identification included indole test, methyl red, voges-proskauer reaction, citrate utilization, nitrate reduction, urea hydrolysis, triple sugar iron agar, rhamnose, maltose, 
dulcitol and ornithine decarboxylase (OIE, 2014). Motility agar was used to test the motility of isolates.

\section{Molecular identification of Salmonella serovars}

DNA extraction was done using DNeasy Blood \& Tissue kit (Qiagen, Hilden, Germany) according to manufacturer's instructions. An overnight pure culture of the bacterial isolate at log phase of growth of each isolate was used for DNA extraction. Species specific oligonucleotide primers targeting $S p e c, S g \lg C$ and $S d f$ I genes were used in multiplex PCR (mPCR) assay for identification of the serotypes as described previously (Yang et al.,2014). The primers used in the mPCR assay are described in Table 1.

Table 1. Primers used in multiplex PCR for identification of $S$. Gallinarum, $S$. Pullorum and S. Enteritidis

\begin{tabular}{|c|c|c|c|c|}
\hline $\begin{array}{l}\text { Primer } \\
\text { name }\end{array}$ & $\begin{array}{l}\text { Forward and reverse } \\
\text { sequences }\end{array}$ & $\begin{array}{l}\text { Salmonella } \\
\text { serovar } \\
\text { identified }\end{array}$ & $\begin{array}{l}\text { PCR } \\
\text { product } \\
\text { (bp) }\end{array}$ & Reference \\
\hline Spec & $\begin{array}{l}\text { SG-F 5’- GAT CTG CTG CCA } \\
\text { GCT CAA- 3' } \\
\text { SG-R 5'- GCG CCC TTT TCA } \\
\text { AAA CAT A -3'; }\end{array}$ & S. Gallinarum & 174 and 252 & Yang et al.,2014 \\
\hline$S g \lg C$ & $\begin{array}{l}\text { SGP F 5'- CGG TGT ACT GCC } \\
\text { CGC TAT -3' } \\
\text { SGP-R 5'- CTG GGC ATT GAC } \\
\text { GCA AA -3' }\end{array}$ & S. Pullorum & 252 & Yang et al., 2014 \\
\hline$S d f I$ & $\begin{array}{l}\text { SE-F 5’- TGT GTT TTA TCT } \\
\text { GAT GCA AGA GG-3' } \\
\text { SE-R) 5'- TGA ACT ACG TTC } \\
\text { GTT CTT CTG G-3' }\end{array}$ & S. Enteritidis & 304 & Yang et al., 2014 \\
\hline
\end{tabular}

Molecular identification of the isolates were carried out in multiplex PCR assay using primer pairs flanking genes specific for each serotype described by Yang et al( 2014) with some modifications. The amplification reaction was carried out in a final volume of $27 \mu$ l comprising $2 \mu l$ nuclease free water, $2 \mu l$ from each primer pair, $10 \mu \mathrm{I} \mathrm{IQ}^{\mathrm{TM}}$ super mix (BIO-RAD, USA) and $3 \mu l$ template. The PCR reaction conditions were 5 minutes at $94^{\circ} \mathrm{C}$ (initial denaturation step), 1 minute at $94^{\circ} \mathrm{C}$ (denaturation step), 1 minute at $55^{\circ} \mathrm{C}$ (annealing step) and 1 minute at $72^{\circ} \mathrm{C}$ (extension step) for 35 cycles with final 2 minutes at $72^{\circ} \mathrm{C}$ (final elongation step) followed by holding at $4^{\circ} \mathrm{C}$. Electrophoresis was run in TAE Buffer by loading $3 \mu \mathrm{l}$ of the PCR product (mixed with loading dye) on $2 \%$ agarose gel wells stained with $2 \mathrm{ul}$ of Ethidium bromide stock solution $(10 \mathrm{mg} / \mathrm{ml})$. 
A parallel lane was also loaded with a 100 bp DNA-marker ladder (Fermantas) and the products were separated at $120 \mathrm{~V}$ for 80 minutes then visualized under UV light and recorded. The expected size of the PCR products flanked by the primer pairs are $174 \mathrm{bp}$ and $252 \mathrm{bp}$ for $S$. Gallinarum, $252 \mathrm{bp}$ for $S$. Pullorum and $304 \mathrm{bp}$ for $S$. Enteritidis.

\section{Experimental animals and management}

A total of 90 white leg horn breed chicken obtained from National veterinary institute (NVI) reared for specific pathogen free (SPF) egg production, were used for the experimental challenge and vaccine efficacy trial. The chickens were kept each in individual cage and were reared and fed according to the recommendations of the production manuals and protocol developed at NVI animal handling facility. At the age of 6 weeks, the serological status of the birds was determined for any antibodies against Salmonella using rapid serum plate agglutination test as described previously (Zancan et al, 2000). The birds which gave negative reaction to Salmonella antigen were used for the experiment. Throughout the experiment, chickens were provided water and feed free of antibiotics. All animal handling and experiments were carried out according to the animal handling and use guidelines stipulated by Research and Ethics Committee of Addis Ababa University, College of veterinary medicine and Agriculture.

\section{Experimental design, immunization and challenge experiment}

Chickens were randomly divided into 2 categories (vaccinated and non-vaccinated control) each comprising 45 birds. Each of these categories were further subdivided and randomly assigned into 3 groups each comprising 15 birds for challenge with each of the three field Salmonella serovars. Immunization was done by subcutaneous administration of live attenuated Salmonella Gallinarum 9R strain vaccine (produced at NVI; batch no Ft 1/2015) containing $2 \times 10^{7}$ CFU per dose.

The Challenge was conducted 2 weeks post vaccination using $S$. Gallinarum, $S$. Pullorum and $S$. Enteritidis strains isolated from cases of salmonellosis. Each group in both vaccinated and non vaccinated category was challenged with the three field serovars (one strain per group) through oral administration of $1 \mathrm{ml}$ of bacterial suspension (in sterile saline) that was in log phase of growth containing $5 \times 10^{7} \mathrm{CFU} / \mathrm{ml}$. McFarland standard (HIMEDIA) was used

Ethiop. Vet. J., 2017, 21 (1), 102-116 
to estimate the bacterial titre where a bacterial suspension adjusted to $0.5 \mathrm{Mc}$ Farland turbidity standard is comparable to contain a bacterial cells of $5 \times 10^{7}$ CFU/ml on plate count (Ben et al., 2010).

\section{Post immunization and post challenge follow-up}

Before the challenge experiment, blood samples were collected from each chicken just before vaccination and, at 1 st and 2 nd week post vaccination to determine the presence of specific antibodies using Rapid Serum Plate Agglutination test (RSPAT) according to Quinn et al.(1994). Birds were observed for 2 weeks post challenge during which development of clinical signs and daily mortality was recorded. Postmortem examination was conducted in all birds that died during the challenge period and in all survivors at day 14 post challenge during which scoring of gross lesions observed was done as described previously (Kiku et al., 2011). Accordingly, gross lesions of enlarged and necrotic foci of the liver and spleen were given scores of: $0,1,2$, or 3 where a score of 0 stands for no lesion, 1 for mild few necrotic foci on liver but not enlarged, 2 for enlarged liver but gizzard not covered and 3 for more severe lesions with gizzard covered with liver. Liver and spleen samples were taken for re-isolation of Salmonella strains from five randomly selected chicken that were sacrificed for postmortem examination at the end of the experiment (day 14).

\section{Data analysis}

All raw data were recorded in MS Excel 2007. Descriptive statistics were used in summarizing clinical data (lesion score and mortality). Mann-Whitney Test was employed for pair-wise comparison of lesion scores between vaccinated and un-vaccinated controls within the respective challenge groups. All analysis was done using SPSS software version 23.

\section{Results}

Isolation and phenotypic characterization of bacteria from suspected cases of salmonellosis outbreak in poultry farms in central Ethiopia resulted in a total of 14 isolates showing cultural, colony and biochemical features consistent with the genus Salmonella which were presumptively identified as 12 of them as $S$. Gallinarum and the remaining two as $S$. pullorum and $S$. Enteritidis. The results of biochemical profile of the isolates are presented in Table 2. 
Table 2. Biochemical profiles of bacterial isolates obtained from suspected cases of salmonellosis in chicken

\begin{tabular}{|c|c|c|c|c|c|c|c|c|c|c|c|c|c|c|}
\hline \multirow[t]{2}{*}{ Test } & \multicolumn{14}{|c|}{ Isolates } \\
\hline & 1 & 2 & 3 & 4 & 5 & 6 & 7 & 8 & 9 & 10 & 11 & 12 & 13 & 14 \\
\hline Motility & - & - & - & - & - & - & - & - & - & - & - & - & - & + \\
\hline $\begin{array}{l}\text { Indole } \\
\text { production }\end{array}$ & - & - & - & - & - & - & - & - & - & - & - & - & - & - \\
\hline Urea hydrolysis & - & - & - & - & - & - & - & - & - & - & - & - & - & - \\
\hline $\begin{array}{l}\text { Ornithine } \\
\text { decarboxylase }\end{array}$ & - & - & - & - & - & - & - & - & - & - & - & - & + & - \\
\hline \multicolumn{15}{|c|}{ Acid production from: } \\
\hline Dextrose & $+/ \mathrm{G}$ & $+/ \mathrm{G}$ & $+/ \mathrm{G}$ & $+/ \mathrm{G}$ & $+/ \mathrm{G}$ & $+/ \mathrm{G}$ & $+/ \mathrm{G}$ & $+/ \mathrm{G}$ & $+/ \mathrm{G}^{-}$ & $+/ \mathrm{G}$ & $+/ \mathrm{G}$ & $+/ \mathrm{G}$ & $+/ \mathrm{G}^{+}$ & $+/ \mathrm{G}$ \\
\hline Lactose & - & - & - & - & - & - & - & - & - & - & - & - & - & - \\
\hline Sucrose & - & - & - & - & - & - & - & - & - & - & - & - & - & - \\
\hline Mannitol & $+/ \mathrm{G}$ & $+/ \mathrm{G}$ & $+/ \mathrm{G}$ & $+/ \mathrm{G}$ & $+/ \mathrm{G}^{-}$ & $+/ \mathrm{G}^{-}$ & $+/ \mathrm{G}$ & $+/ \mathrm{G}$ & $+/ \mathrm{G}$ & $+/ \mathrm{G}$ & $+/ \mathrm{G}$ & $+/ \mathrm{G}$ & $+/ \mathrm{G}^{+}$ & $+/ \mathrm{G}^{-}$ \\
\hline Maltose & $+/ \mathrm{G}$ & $+/ \mathrm{G}$ & $+/ \mathrm{G}$ & $+/ \mathrm{G}$ & $+/ \mathrm{G}$ & $+/ \mathrm{G}$ & $+/ \mathrm{G}$ & $+/ \mathrm{G}$ & $+/ \mathrm{G}$ & $+/ \mathrm{G}$ & $+/ \mathrm{G}$ & $+/ \mathrm{G}$ & - & $+/ \mathrm{G}$ \\
\hline Dulcitol & $+/ \mathrm{G}$ & $+/ \mathrm{G}$ & $+/ \mathrm{G}$ & $+/ \mathrm{G}$ & $+/ \mathrm{G}$ & $+/ \mathrm{G}$ & $+/ \mathrm{G}$ & $+/ \mathrm{G}$ & $+/ \mathrm{G}$ & $+/ \mathrm{G}$ & $+/ \mathrm{G}$ & $+/ \mathrm{G}$ & - & $+/ \mathrm{G}^{-}$ \\
\hline Rhamnose & - & - & - & - & - & - & - & - & - & - & - & - & + & - \\
\hline Interpretation & \multicolumn{12}{|c|}{ S. Gallinarum } & $\begin{array}{l}\text { S. } \\
\text { Pullorum }\end{array}$ & $\begin{array}{l}\text { S. } \\
\text { Enteritidis }\end{array}$ \\
\hline
\end{tabular}

Symbols: $+/ \mathrm{G}^{-}$, fermented without gas production; $+/ \mathrm{G}^{+}$, fermented with gas production; 1-13 isolates identified as $S$ Gallinarum;

13, isolate identified as $S$. Pullorum; 14, isolate identified as $S$. Enteritidis

Molecular identification of the isolates employing multiplex PCR with specific primers was consistent with the phenotypic (presumptive) identification further confirming the isolates to be $S$. Gallinarum, $S$. Pullorum and $S$. Enteritidis. Twelve samples showing amplification of speC and $g \lg C$ genes with PCR products of 174 and $252 \mathrm{bp}$ were identified as $S$. Gallinarum, one isolate with $304 \mathrm{bp}$ product as $S$. Enteritidis while one isolate with only one $252 \mathrm{bp}$ was identified as S. Pullorum. (Figure 1).

Assessment of immune status of chickens used for the challenge experiment for Salmonella infection just before immunization with $S$. Gallinarum 9R vaccine showed that all of them were sero-negative. 


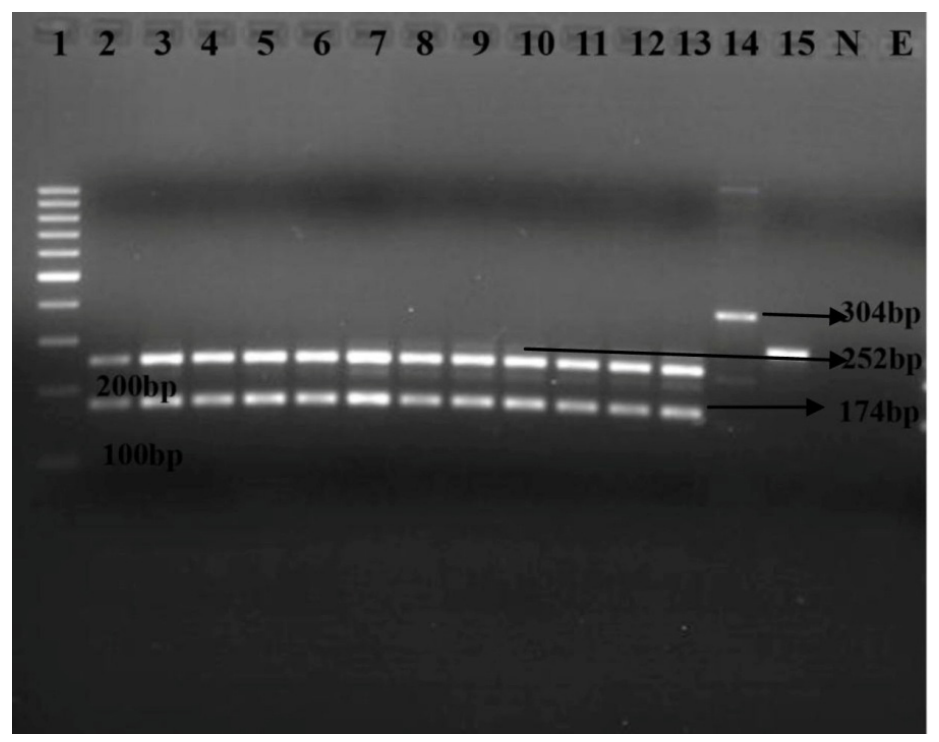

Figure 1. Agarose gel electrophoresis of multiplex PCR of 14 Salmonella isolates obtained from cases suspected of salmonellosis in poultry farms in central Ethiopia.

Lanes 1: 100bp molecular marker or ladder (Fermentas); Lanes 2-13:Isolates positive for SpeC (174bp) and SglgC (252bp) genes; Lane 14: Isolate positive for $S d f I(304 \mathrm{bp})$ gene; Lane 15: Isolate positive for $\operatorname{Sg} \lg C$ (252bp) gene only; Lane N: Negative control without templateLane E: Extraction control (Rnase free water)

The percentages of chicken detected as sero-positive after vaccination ranged from $80 \%$ at $1^{\text {st }}$ week post vaccination to peak values of $95.6 \% 2$ weeks post vaccination. The findings of the immune response of vaccinated birds with $S$. Gallinarum $9 \mathrm{R}$ vaccine is presented in Table 3.

Table 3. Antibody response of birds after vaccination with $S$. Gallinarum 9 R vaccine

\begin{tabular}{lccc}
\hline Time intervals & $\begin{array}{l}\text { No of tested } \\
\text { samples }\end{array}$ & $\begin{array}{l}\text { No of } \\
\text { positive samples }\end{array}$ & Proportion (\%) \\
\hline 0 (just before Vaccination) & 45 & 0 & 0 \\
7 days & 45 & 36 & 80 \\
14 days & 45 & 43 & 95.6 \\
\hline
\end{tabular}


The protective efficacy and lesion scores in vaccinated and unvaccinated groups are presented in Table 4. In the vaccinated group, no mortality was observed in $S$. Gallinarum challenged group despite that three chicken showed slight depression and weakness, and pinpoint hemorrhages on the liver and spleenomegaly during post-mortem examination. However, in the corresponding nonvaccinated group, 8 (53.3\%) birds died with gross lesions in internal organs on postmortem, 5 (33.4\%) showed macroscopic lesions with the remaining 2 (13.4\%) showing no lesion in internal organs during postmortem examination.

In $S$. Pullorum challenged group, a single chicken from the immunized group had macroscopic lesion with no record of mortality while in the un-immunized group, 2 chickens died, 13 (86.7\%) showed post-mortem lesion and $10(66.7 \%)$ were with prolonged depression. In groups challenged with $S$. Enteritidis, no mortality and macroscopic lesion was observed in the immunized group while $10(66.7 \%)$ showed postmortem lesion, $9(60 \%)$ of them with slight depression and no records of mortality in un-immunized group. There was significant difference $(p<0.05)$ in mean lesion scores between vaccinated and non-vaccinated controls in both $S$. Gallinarum and $S$. Pullorum challenged groups with higher lesion severity in non-vaccinated chicken (Table 4).

Table 4. Mortality and lesions after challenge with S. Gallinarum, S. Pullorum and $S$. Enteritides field strains

\begin{tabular}{|c|c|c|c|c|c|c|}
\hline $\begin{array}{l}\text { Challenge } \\
\text { groups }\end{array}$ & $\begin{array}{l}\text { Immunization } \\
\text { status }\end{array}$ & $\begin{array}{l}\text { No per } \\
\text { group }\end{array}$ & $\begin{array}{l}\text { No of Birds } \\
\text { with lesions }\end{array}$ & $\begin{array}{l}\text { Mean } \\
\text { lesion } \\
\text { score } \pm \mathrm{SD}\end{array}$ & P-value & Mortality \\
\hline \multirow{2}{*}{$\begin{array}{l}\text { S.Gallinarum } \\
\text { group }\end{array}$} & Vaccinated & 15 & 3 & $0.2 \pm 0.41$ & \multirow[t]{2}{*}{$\mathrm{p}<0.05$} & $0(0 \%)$ \\
\hline & Control * & 15 & 5 & $2.4 \pm 1.05$ & & $8(53.4)$ \\
\hline \multirow{2}{*}{$\begin{array}{l}\text { S. pullorum } \\
\text { Group }\end{array}$} & Vaccinated & 15 & 1 & $0.07 \pm 0.26$ & \multirow[t]{2}{*}{$\mathrm{p}<0.05$} & $0(0 \%)$ \\
\hline & Control * & 15 & 13 & $1.87 \pm 0.83$ & & $2(13.3)$ \\
\hline \multirow{2}{*}{$\begin{array}{l}\text { S.Enteritidis } \\
\text { Group }\end{array}$} & Vaccinated & 15 & & 0 & \multirow[t]{2}{*}{-} & $0(0 \%)$ \\
\hline & Control * & 15 & 10 & $0.48 \pm 0.67$ & & $0(0 \%)$ \\
\hline Total & & 90 & 32 & & & 10 \\
\hline
\end{tabular}

*Control represent unvaccinated group.

Strains of bacteria used in the challenge experiment (S. Gallinarum, S. Pullorum and $S$. Enteritidis) were re-isolated and identified (using both biochemical and molecular methods) from internal organs (liver, spleen, and caecum) of chicken in unvaccinated groups 14 days after challenge but none from vaccinated groups (Table 5). 
The current study showed that the live attenuated $S$. Gallinarum 9R strain vaccine provided significant protection against the most virulent strain of $S$. Gallinarum as well as cross protection against challenge with $S$. Pullorum and $S$. Enteritidis.

Table 5. Recovery of challenge strains from the internal organs of chicken 2 weeks post challenge

\begin{tabular}{|c|c|c|c|c|c|c|}
\hline \multirow[t]{2}{*}{ challenge strains } & \multicolumn{2}{|c|}{ S. Gallinarum } & \multicolumn{2}{|c|}{ S. Pullorum } & \multicolumn{2}{|c|}{$S$. Enteritidis } \\
\hline & vaccinated & Control & Vaccinated & Control & vaccinated & Control \\
\hline $\begin{array}{l}\text { No. of chickens } \\
\text { examined for } \\
\text { bacteriology }\end{array}$ & 5 & 5 & 5 & 5 & 5 & 5 \\
\hline $\begin{array}{l}\text { No. of chickens } \\
\text { from which } \\
\text { bacteria } \\
\text { recovered (from } \\
\text { both liver and } \\
\text { spleen samples) }\end{array}$ & $0(0 \%)$ & $3(60 \%)$ & $0(0 \%)$ & $4(80 \%)$ & $0(0 \%)$ & $4(80 \%)$ \\
\hline
\end{tabular}

\section{Discussion}

Commercial poultry farming is one of the fastest growing sectors in Ethiopia with most farms concentrated around major cities in the central part of the country. One of the challenges of the growing poultry industry is salmonellosis causing heavy economic loss through mortality and reduced productivity. Morphological, biochemical and staining features of Salmonella strains isolated from suspected cases of salmonellosis outbreaks conform to the typical characteristics of Salmonella and were consistent with previous similar studies (Robinson et al., 2000; Rahman, 2003; Khan et al.,1998; Sujatha et al., 2003; Perez.et al., 2004; OIE, 2014). Molecular identification of the isolates based on serotype specific primers in multiplex PCR (mPCR) assay including one isolate that cannot be presumptively identified phenotypically showed the fidelity and discriminatory power of the multiplex PCR to provide rapid and definitive detection of Salmonella serotypes (Shah et al., 2005).

The isolation of a single isolate of Salmonella Enteritidis from internal organs from cases of salmonellosis indicates the invasive characteristics of the isolate which was also observed in its re-isolation from internal organs (liver and 
spleen) of experimentally infected control birds in the challenge experiment. This unusual isolation of this serovar from salmonellosis outbreaks in poultry in the current study along with $S$. Gallinarum, and $S$. Pullorum, may alarm the emergence of population shifts in Salmonella serovars involved in salmonellosis. Such scenario appears to be driven by a combination of factors related to bacterial genotype, host, and management practices (Foley et al., 2011). This had important implication on the success of preventive measures through vaccination since the protective efficacy of the currently used live attenuated Salmonella Gallinarum 9R vaccine may be reduced or absent against antigenically dissimilar serovars (Foley et al., 2011). This suggests regular surveillance of Salmonella serotypes involved in cases of salmonellosis and evaluation of vaccine efficacy on the prevailing serovars is essential.

Developing protective measures against Salmonella infections in chicken including vaccination strategy, is one of the most important issues in the poultry industry (Lee et al., 2005; Van Immersel et al., 2005). The efficacy and usefulness of the live attenuated Salmonella Gallinarum 9R strain vaccine against Salmonella infections has been documented by several workers (Smith 1956; Harbourne, 1957; Harbourne et al., 1963; Lee et al., 2007).

In the current study, the immune response observed due to vaccination using live attenuated Salmonella Gallinarum 9R strain in a significant proportion of birds complements the findings of Yamane et al (2000) and Barrow et al (1990). The results of this also study concedes with the findings of Feberwee $e t$ al (2001a) that showed the significant protective efficacy of $S$. Gallinarum 9R strain vaccine against challenge with $S$. Gallinarum as well as cross protection against $S$. Pullorum and $S$. Enteritidis. Previous studies also indicated that this vaccine may also provide some protection against Salmonella Enteritidis and Salmonella Typhimurium (Barrow et al., 1990; Audisio and Terzolo, 2002).

The cross protection by Salmonella Gallinarum, 9R strain vaccine observed in the current study is due to the fact that Salmonella Gallinarum, Salmonella Pullorum and Salmonella Enteritidis are classified as group D Salmonella (Kauffman- White scheme) implying that they share similar antigenic structure (O-antigens 1, 9 and 12) (Ochoa-Repa'raz et al., 2004; Forshell and Wierup, 2006). The higher virulence of the wild strain of $S$. Gallinarum as observed in the challenge experiment in non-vaccinated chicken might be associated with its immunogenicity (Wigley et al., 2005). The high level of antibody 
response in vaccinated hens was considered to be due to the high agglutination property of the bacterial cells.

Immunization with Salmonella Gallinarum 9R strain vaccine can also greatly reduce the severity of the disease in affected birds as observed in the current study where significantly lower lesion severity was recorded in few of the vaccinated chicken showing clinical signs compared to the unvaccinated controls. This is further complemented by the absence of Salmonella strains during reisolation from internal organs in the vaccinated chicken unlike that of nonvaccinated groups challenged with any of the Salmonella strains indicating effective clearance of the bacteria by the immune system in vaccinated groups two weeks after challenge.

In conclusion, vaccination with live Salmonella Gallinarum 9R strain vaccine resulted in sero-conversion in significant number (about 95\%) of vaccinated chicken and conferred effective protection against experimental challenge with Salmonella Gallinarum, Salmonella Pullorum and invasive strains of Salmonella Enteritidis proving its cross protective ability and usefulness as a vaccine against poultry salmonellosis in Ethiopia.

\section{Acknowledgements}

We thank the National Veterinary Institute (NVI) for funding the study and staffs at Live Bacterial Vaccine Production and Research and Diagnosis Laboratories (NVI) for their technical support during the research work.

\section{References}

Audisio, M..C. and Terzolo, H.R., 2002. Virulence Analysis of a Salmonella Gallinarum strain by oral inoculation of 20-day-old chickens. Avian Dis., 46, 186-91.

Barbour, E.K. Jurdi, . L.H., Talhouk, R., Qatanani, M., Eid, A., Sakr, W., Bouljihad, M . and Spasojevic R. , 1999. Emergence of Salmonella Enteritidis outbreaks in broiler chickens in the Lebanon: epidemiological markers and competitive exclusion control. Rev. sci. tech. Off. int. Epiz. 18, 3, 710-718

Barrow, P.A., Lovell, M.A. and Berchiri, A., 1990. Immunization of laying hens against Salmonella Enteritidis with a live attenuated vaccine. Vet. Res. microbiol., 126,

241- 42 
Feberwee, A., Hartman, E.G., De Wit, J.J. and De Vries, T.S., 2001. The spread of Salmonella Gallinarum 9R vaccine strain under field conditions. Avian Dis., 45, 1024-29.

Foley, S.L., Nayak, R., Hanning, I.B., Johnson, T.J., Han, J.and Ricke, S.C.,2011. Population Dynamics of Salmonella enterica Serotypes in Commercial Egg and Poultry Production. Appl. Environ. Microbiol., 77, 4273-4279.

Forshell, L.P.and Wierup, M.,2006. Salmonella contamination: a significant challenge to the global marketing of animal food products. Rev. Sci. Tech. Offi. Int. Des Epi$z 0 ., 25,541-554$.

Freeman, B.A. 1985. Burrows text book of microbiology. $22^{\text {nd }}$ ed. Saunders W B Company; Pp. 464- 472

Gast, R. K., 1997. Salmonella infection. In: Calnek, B.W., Barnes, H. J., Beard, C.W., McDougald, L.R., Saif, Y.M. (EDs). Diseases of poultry, 10th ed. , Iowa State University Press; Pp. 81-93.

Harbourne, J.F.,1957.The control of fowl typhoid in the field by the use of live vaccines. Vet. Rec., 69,1102-1107.

Harbourne, J.F., Williams, B.M., Parker, W.H.and Fincham, I.H., 1963. The prevention of fowl typhoid in the field using a freeze-dried 9R vaccine. Vet. Rec., 75, 858-861.

Hinton M. T, E.J. Threlfall Z and B. Rowe, 1990. The invasiveness of different strains of Salmonella enteritidis phage type 4 for young chickens. FEMS Microbiol. Lett., 70,193

Khan, A., Bari, A., Islam, M.R. Das, P. and Ali, M., 1998. Pullorum disease in semi mature chickens and its experimental pathology. Bangla. Vet. J., 32,124-128.

Kiku, M., Atul, A.C.and John, H. L.,2011. Safety and efficacy of a virulence gene-deleted live vaccine candidate for fowl typhoid in young chickens. Avian Pathol., 40 ,309-314.

Lee, Y.J., Mo, I.P.and Kang, M.S.,2007. Protective efficacy of live Salmonella Gallinarum 9R vaccine in commercial layer flocks. Avian Pathol., 36,495-498.

Lee, Y.J., Mo, I.P.and Kang, M.S.2005. Safety and efficacy of Salmonella Gallinarum 9R vaccine in young laying chickens. Avian Pathol.34., 362-366.

Ochoa-Repa'raz, J., Sesma, B., A’ lvarez, M., Renedo, M.J., Irache, J.M.and Gamazo, C., .2004. Humoral immune response in hens naturally infected with SalmonellaEnteritidis against outer membrane proteins and other surface structural antigens. Vet. Res., 35, 291-298.

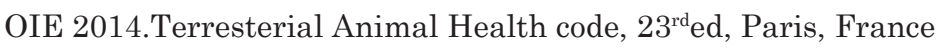


Perez, C., Rivera, S., Pirela, A., Rincon, H., Mavarez, Y. and Roman, R.,.2004. Isolation of Salmonella in poultry carcasses and evaluation of the effectiveness of different enrichment and selective media. Revista Cientifica Facultad CienciasVeterinarias Universidad del Zulia, 14,177-185.

Quinn, P.J., Markey, B, K., Carter, M, E., Donnelly, W.J.and Leonard, F.C. 1994. Veterinary Microbiology and Microbial Disease. London: Blackwell Publishing; Pp. 273- 279.

Rahman, M.,2003. Growth of poultry industry in Bangladesh: Poverty alleviation and employment. In: Proceedings of $3{ }^{\text {rd }}$ International Poultry Show and Seminar, from February 28 to March 2, 2003, held in Bangladesh. China Friendship Conference Centre (BCFCC) at Sher-e-Bangla Nagar, Dhaka, Bangladesh, 2003. Pp. 1-7

Robinson, H., Mdegela, M.G.S., Yongolo, U., Minga, M. and Johin, E., 2000. Molecular Epidemiology of Salmonella Gallinarumin chickens in Tanzania. Avian Pathol., 29, 457-463.

Shah, D.H., Park, J., Cho, M., Kim, M.and Chae, J., 2005. Allele-specific PCR method based on $r f b S$ sequence for distinguishing Salmonella Gallinarum from Salmonella Pullorum: serotype-specific $r f b S$ sequence polymorphism. J. Microbiol. Methods, 60,169-177.

Shivaprasad, H.L., 1997. Pullorum disease and fowl typhoid. In: Calnek, B.W., Barnes, H. J., Beard, C.W., McDougald, L.R., Saif, Y.M., editors. Diseases of poultry, $10^{\text {th }}$ ed. Iowa State University Press; Pp. 82-96.

Smith, H.W.,1956. The use of live vaccines in experimental Salmonella Gallinaruminfection in chickens with observations on their interference effect. J. Hyg. Camb., 54, 419-432.

Sujatha, K., Dhanalakshmi, K. and Rao, A.S., 2003. Isolation and characterisation of Salmonella Gallinarum from chicken. Indian Vet. J., 80, 473-474.

Threlfall, E. J.and Frost, J. A., 1990. The identification, typing and fingerprinting of Salmonella: laboratory aspects and epidemiological applications. J. Appl. Bacteriol., 69, 5-19.

Van Immersel, F., Methner, U., Rvchlik, I., Velge, P., Martin, G., Foster, N., Ducatelle, R. and Barrow, P.A.,2005. Vaccination and early protection against non-host-specific Salmonella serotypes in poultry: exploitation of innate and microbial activity. Epidemiol. Infect. 33, 959-978.

Wigley, P., Hulme, S., Powers, C., Beal, R., Smith, A. and Barrow, P.,2005) Oral infection with the Salmonella enterica serovar Gallinarum 9R attenuated live vaccine as a model to characterize immunity to fowl typhoid in chicken. BMC Vet. Res., 1,1-6. 
Yamane, Y., Leonard, J.D., Kobatake, R., Awamura, N., Toyota, Y., Ohat, H., Otsuki,K.. and Inoue, T..2000. A case study on Salmonella Enteritidis (SE), Origin at three egg laying farms and its control with $S$. Enteritidis bactrin. Avian Dis., 44, 519 -526 .

Yang, L., Lou, Y., Su, C., Zhang, H., Guan, M., Xu, C., Chen, S., Wei, R., Chen, J. and Peng, D. .2014. Development of a multiplex PCR for Rapid Identification of Salmonella Enteritidis, Salmonella Typhimurium, Salmonella Pullorum and Salmonella Gallinarum. Acta Vet. Zootechnica Sinica, 45, 268-273

Zancan, F,B., Berchieri, Jr. A., Fernandes, S.A. and Gama, N.M., 2000. Salmonella spp investigation in transport box of day old birds. Braz. J. Microbiol., 31,230-232. 